\title{
Study of Ti-7.5Si-22.5B Alloys Produced by Powder Metallurgy
}

\author{
Bruno Bacci Fernandes ${ }^{\mathrm{a}, \mathrm{b} *}$, Carlos de Moura Neto ${ }^{\mathrm{a}}$, Alfeu Saraiva Ramos ${ }^{\mathrm{c}}$, \\ Francisco Cristóvão Lourenço de Melo ${ }^{\mathrm{d}}$, Vinícius André Rodrigues Henriques ${ }^{\mathrm{d}}$
}

\author{
anstituto Tecnológico de Aeronáutica, CEP 12228-900, São José dos Campos, SP, Brazil \\ 'Instituto Nacional de Pesquisas Espaciais, CEP 12228-010, São José dos Campos, SP, Brazil \\ ${ }^{\mathrm{c}}$ Universidade Federal de Alfenas - UNIFAL-MG, CEP 37715-400, Poços de Caldas, MG, Brazil \\ ${ }^{\mathrm{d} I n s t i t u t o}$ de Aeronáutica e Espaço, CEP 12228-904, São José dos Campos, SP, Brazil
}

Received: June 27, 2013; Revised: April 8, 2014

\begin{abstract}
Refractory alloys with silicides and borides have been used in high temperature applications because their elevated melting point, good oxidation resistance and high strength-to-weight ratio. The present study approaches the preparation of Ti-7.5Si-22.5B (at.-\%) alloys through high-energy ball milling and sintering. The powders and compacts obtained in these processes were characterized by X-ray diffraction (XRD), scanning electron microscopy (SEM), density measurements, chemical analyses and Vickers hardness. It was verified that silicon and boron powders are dissolved in the titanium during milling with an iron contamination up to 6.0 at.- $\%$. Furthermore, the use of short milling times and alcohol during the final stages of milling increases the powder yield. Such increasing was obtained even with a high rotary speed $(300 \mathrm{rpm})$, which generally creates higher temperatures and consequently more sticking. After sintering of the as-milled powders, it was indentified mainly the $\mathrm{Ti}+\mathrm{Ti}_{6} \mathrm{Si}_{2} \mathrm{~B}+\mathrm{TiB}+\mathrm{Ti}_{5} \mathrm{Si}_{3}$ phases in the Ti-7.5Si-22.5B sintered alloys, which presented hardness values up to $800 \mathrm{HV}$. The materials produced by the present work can be employed in coating research as sputtering targets.
\end{abstract}

Keywords: powder metallurgy, titanium alloys, vickers hardness

\section{Introduction}

The development of new compositions according to phase diagrams of the Ti-Si-B system is one of the main ways to obtain and investigate new titanium alloys with improved properties. Analysis of thermomechanical treatments on composition, morphology and volume fractions of phases is fundamental to improve such development ${ }^{1}$. These titanium alloys have been used in structural applications at high temperatures and as a protective layer in drilling tools obtained through magnetron sputtering or other techniques ${ }^{2-4}$. Furthermore, $\mathrm{Ti}_{5} \mathrm{Si}_{3}$ phase has high technological importance ${ }^{5}$, titanium borides present an excellent combination of properties ${ }^{6,7}$ and there is limited information about the $\mathrm{Ti}_{6} \mathrm{Si}_{2} \mathrm{~B}$ phase ${ }^{8}$.

High-energy ball milling (HEBM) has been used in the processing of complex materials instead conventional melting techniques. This solid-state technique allows phase transformations in non-equilibrium thermodynamic conditions, which modify the Gibbs' free energy of the processed system ${ }^{9,10}$. However, the temperature increasing in the milling vessels may decrease lattice defects and metastable structures. HEBM of ductile components in high proportions generate excessive sticking due to the plastic deformation and cold welding. Milling times must be chosen carefully to achieve an optimal level between dissolution/ amorphization and sticking of particles avoiding milling

*e-mail: brunobacci@yahoo.com.br for an excessive time. Nitrogen and oxygen contamination occurs when reactive powders (e.g. titanium) are milled in improperly sealed containers. Such contamination can promote the formation of fcc nitride phase after amorphous phase and solid solution, e.g., during milling of Ti-24Al (wt.\%) alloy. Other contaminants can also be derived from the milling media and raw materials. Sintering of materials processed by HEBM can provide benefits, such as formation of structures with more interfaces of different compositions and nanocrystalline and/or amorphous phases, besides incorporation of impurities. The stored energy during milling can contribute to the development of metastable structures which, when released during sintering, may decrease the temperature and time for a desired densification ${ }^{9,11}$. HEBM also reduces stresses and crack formation during sintering as well as produces compacts with closed porosity after pressureless sintering ${ }^{12}$.

Recently, HEBM experiments have been performed on the Ti-Si, Ti-B and Ti-Si-B systems ${ }^{13-18}$. These works have shown reductions of the boron and silicon XRD peaks and even the disappearance of these peaks with longer milling times. Such evidence indicates that happenned a partial dissolution of these atoms in the $\alpha$-titanium lattice, i.e. a supersaturated solid solution. Depending of the milling time, amorphous and/or nanocrystalline structures were also detected in these works. Other research in this area shows that if the difference between sintering and eutectic 
melting temperatures is around only $50^{\circ} \mathrm{C}$, part of the Ti-Si alloy is melted. At this condition, such melting partially ruins the silicide skeleton and shrinkages the liquid under capillary forces, which occurs due to the heat released from the silicide formation ${ }^{4}$.

New methods for production of titanium alloys are necessary nowadays to reduce their costs and improve their properties. The present manuscript reports results based on the production of Ti-7.5Si-22.5B sintered alloys by HEBM and sintering. New milling parameters were used in order to improve the powder yield of this composition after the achievement of mechanical alloying. Milling and sintering effects on the predictable phases as well as contamination levels were also verified after the powder metallurgy processes by XRD, SEM, density measurements, hardness and chemical analyses of nitrogen/oxygen.

\section{Experimental Procedure}

High-purity powders described elsewhere ${ }^{15}$ were used on the preparation of Ti-7.5Si-22.5B (at.-\%) samples. The powders in the stoichmetric composition of the alloy were mixed in a planetary Fritsch P-5 ball-mill. The milling was performed up to 32 hours in argon atmosphere (White Martins, São Paulo, Brazil, purity of 99.999\%) and with a rotary speed of $300 \mathrm{rpm}$. Manipulations were carried out in a glove box filled with argon gas because the problem of safety hazards in handling fine powders. Two different milling routes (MR) were employed to evaluate their stored energy and powder yield: (i) MR 1: The process was paused for 5 minutes in every 2 minutes of milling, using 12 balls of 12-mm diameter, 6 balls of 16-mm diameter and 6 balls of 19 -mm diameter. The total time was 32 hours, being 30 hours in dry medium followed by 2 hours in isopropyl alcohol. (ii) MR 2: The process was paused for 1 minute in every 10 minutes of milling. The total time was 1.3 hours, being 1 hour in dry medium followed by 0.3 hour in isopropyl alcohol. The second milling route was performed with two different ball sets: (i) MR 2a: 12 balls of 12-mm diameter, 6 balls of 16-mm diameter and 6 balls of $18-\mathrm{mm}$ to $19-\mathrm{mm}$ diameter; and (ii) MR 2b: 12 balls of 12-mm diameter, 8 balls of 16-mm diameter, 6 balls of $18-\mathrm{mm}$ diameter and 40 balls of $3-\mathrm{mm}$ diameter. These milling processes were carried out using 304 stainless steel vials and balls, and a ball-to-powder weight ratio of 10:1. The mass of the as-milled powders was measured at the end of each MR in order to calculate their yield.

Aiming to obtain green samples with $10-\mathrm{mm}$ diameter and thickness of 4 to $25 \mathrm{~mm}$, some as-milled Ti-7.5Si22.5B powders were uniaxially pressed using loads between 80 and $230 \mathrm{MPa}$. Such green samples have their densification increased through cold isostatic pressing using loads between 200 and $450 \mathrm{MPa}$, with the exception of as-milled powders processed for 30.3 hours that were subsequently sintered under high vacuum (HV). The sintered alloys were obtained through pressureless sintering (PS) at $1100-1200^{\circ} \mathrm{C}$ under low vacuum (LV) or $\mathrm{HV}$, or after hot pressing (HP) under argon atmosphere $\left(900^{\circ} \mathrm{C} / 30 \mathrm{MPa}\right)$. The dwell time at the threshold was 4 hours (LV), 2 hours (HV), and 40-50 minutes (HP). The final dimensions of such compacts were 10-mm diameter and thickness varying from 3 to $19 \mathrm{~mm}$.

XRD patterns were obtained at room temperature in a Philips diffractometer (with $\mathrm{CuK} \alpha$ radiation) using $40 \mathrm{kV}$ and $20 \mathrm{~mA}$. Intensity data were collected by the step counting method (step of $0.05^{\circ}$, and a time per step of $2.5 \mathrm{~s})$ in the range $2 \theta\left(20^{\circ}-80^{\circ}\right)$. The crystallographic phase data of the followed phases available in the literature were utilized: $\mathrm{Ti}_{\mathrm{ss}}, \mathrm{TiB}, \mathrm{Ti}_{3} \mathrm{~B}_{4}, \mathrm{TiB}_{2}, \mathrm{Ti}_{5} \mathrm{Si}_{3}, \mathrm{Ti}_{5} \mathrm{Si}_{4}, \mathrm{TiSi}$, $\mathrm{TiFe}, \mathrm{TiSi}_{2}, \mathrm{Si}_{\mathrm{ss}}, \mathrm{B}, \mathrm{Ni}_{3} \mathrm{~B}_{2} \mathrm{O}_{6}$, and $\mathrm{FeO}^{[19]}$. Crystallographic information of the $\mathrm{Ti}_{6} \mathrm{Si}_{2} \mathrm{~B}$ phase was the published by Ramos $^{8}$. Characterization of morphology and composition of the Ti-Si-B samples were performed through SEM. Powders were deposited on adhesive tape fixed to specimen tabs prior to SEM measurements. EDS attached to SEM was used for quantitative chemical analysis of the materials.

Hardness was measured using a Vickers microhardness device (Micromet 2004, Buehler) using 200-gf load. Average and standard deviation were calculed from five indentations per samples. Average contents of oxygen and nitrogen were determined using a LECO TC-500 inert gas fusion analyzer from two measurements per sample.

\section{Results and Discussion}

High values of powder yield - around $86 \%$ in dry medium, reaching an accumulated of $96 \%$ after more 20 minutes in wet medium - were registered for the MR 2 probably due to the lower time used (1.3 hour) instead the lower pause frequency. Normally, higher pause frequency would reduce the temperature and powder sticking, however milling time in this case, was the dominant parameter. As visually observed in the vessels processes through the MR 1, powder sticking increases significantly after 5 hours. Powder yield around 13\% was registered after 30 hours of dry milling through the MR 1 , which was increased to an accumulated of $65.9 \%$ due to the use of alcohol during 2 hours. These results are higher than previous experiments with the same composition ${ }^{15}$ and close to that obtained with different compositions ${ }^{17}$. The use of different ball sizes does not improve the powder yield, but promotes minor changes in morphology of the powders.

After milling of Ti-7.5Si-22.5B powders for 1 hour, only $\alpha$-titanium peaks are observed in XRD patterns (Figure 1), implying that silicon and boron were dissolved in this hcp phase $^{9,13-18}$. MR 2a achieves the lower intensity values of the titanium peaks that could be related to a higher milling efficiency using such configuration. However, such short milling times present significant variation on chemical composition for the whole mass of the powder mixtures, what must be the main reason for these intensity differences, as well as for the shift in peak positions.

As shown in Figure 2a, the MR 1 produced the lower particle sizes (maximum of $250 \mu \mathrm{m}$ ) after 1 hour. However, the MR 2a and 2b generated larger particles (maximum of $1000 \mu \mathrm{m}$ ), despite their differences in the XRD results (Figure 1). The broad peak after 5 hours of milling through the MR 1 denotes amorphous and/or highly disordered phases. Peak angular displacements and a new peak at $37.6^{\circ}$ suggest the formation of fcc titanium or an intermetallic phase, e.g. $\mathrm{Ti}_{6} \mathrm{Si}_{2} \mathrm{~B}, \mathrm{Ti}_{3} \mathrm{Si}$ or $\mathrm{TiSi}_{2}$ (Figure 3). 


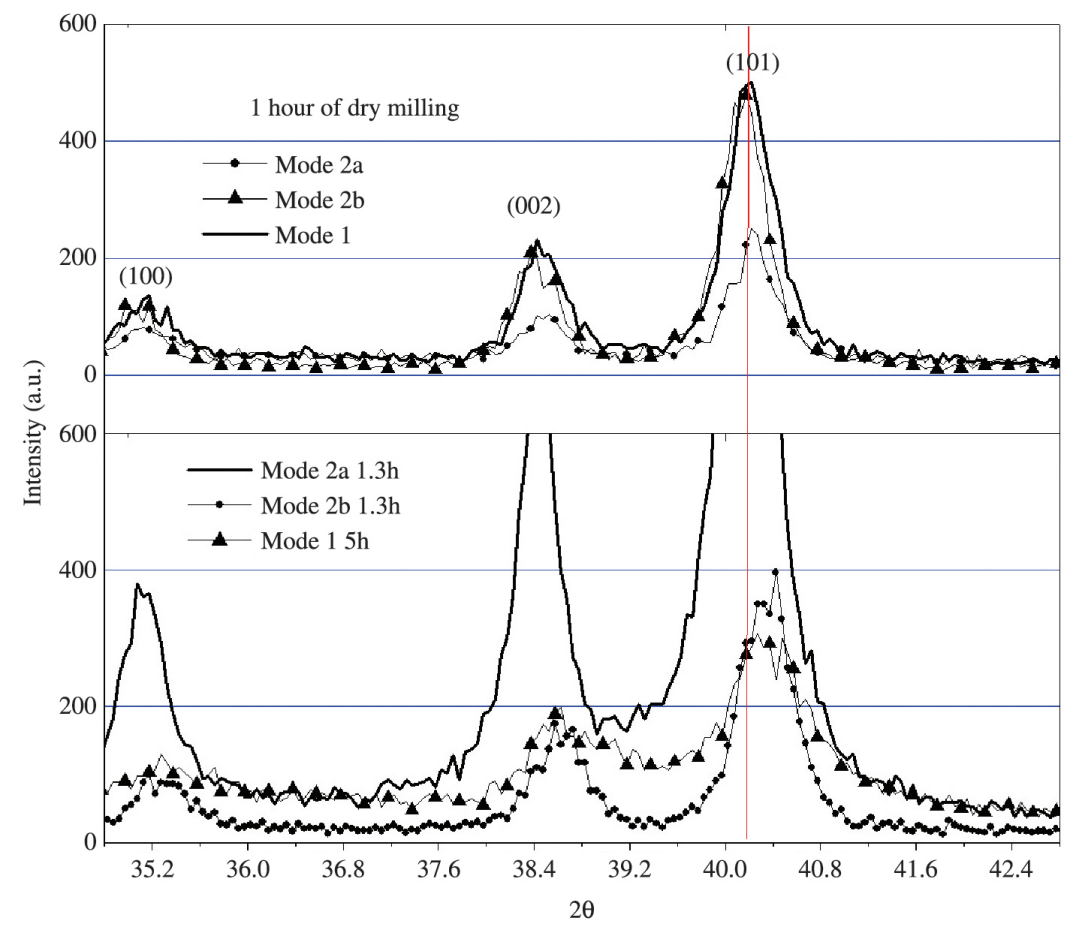

Figure 1. XRD results of Ti-7.5Si-22.5B powders obtained through different MR's. Vertical line concerns the main peak of $\alpha$-titanium.

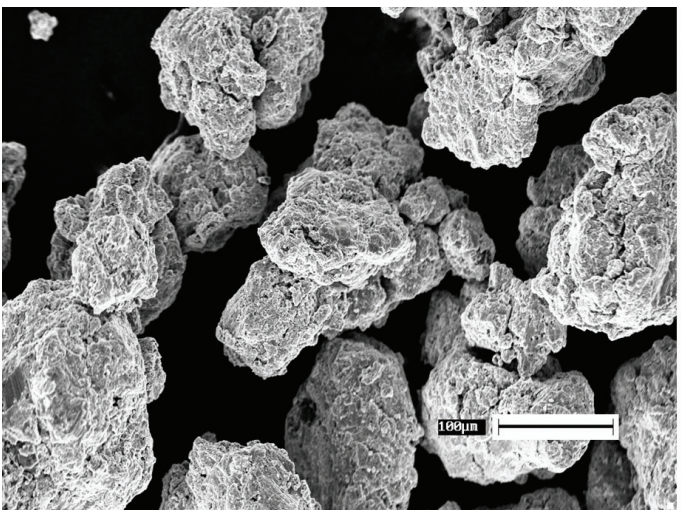

(a)

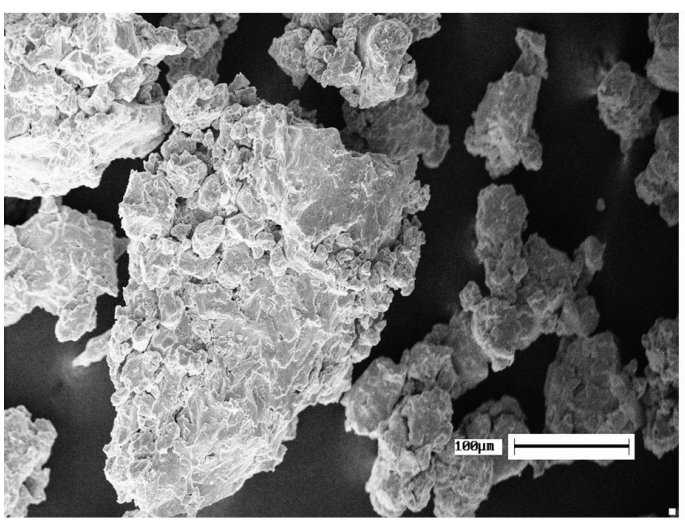

(c)

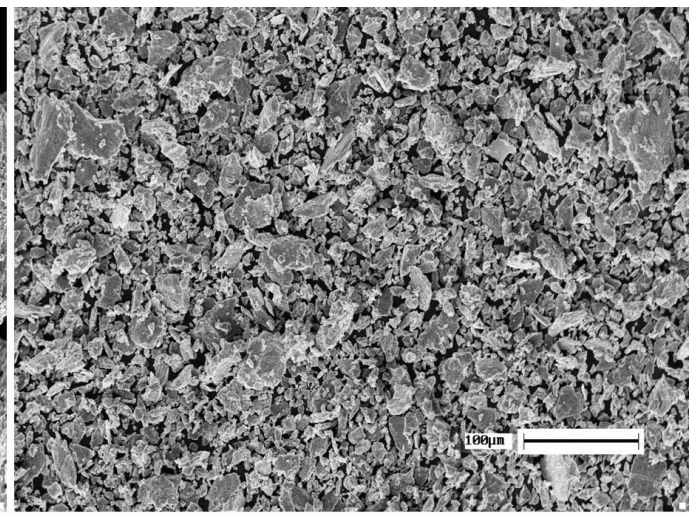

(b)

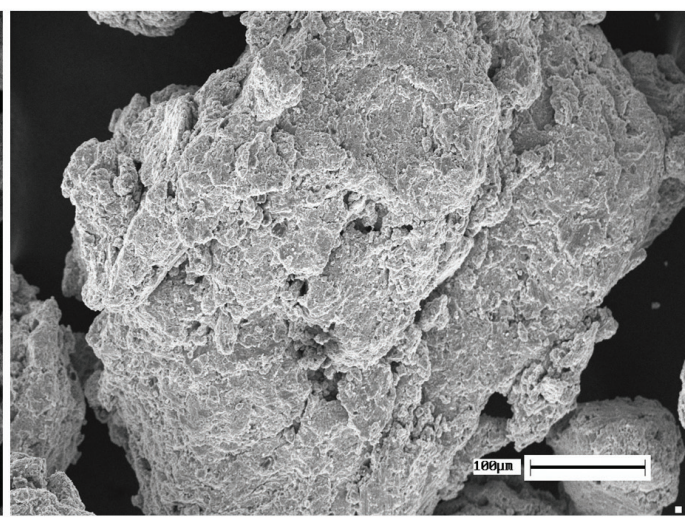

(d)

Figure 2. SEM images of the as-milled Ti-7.5Si-22.5B powders processed for: (a) 1 hour (MR 1); (b) 30 hours in dry medium followed by 1 hour in wet medium (MR 1); (c) 30 hours (MR 1); and (d) 1 hour (MR 2a). 


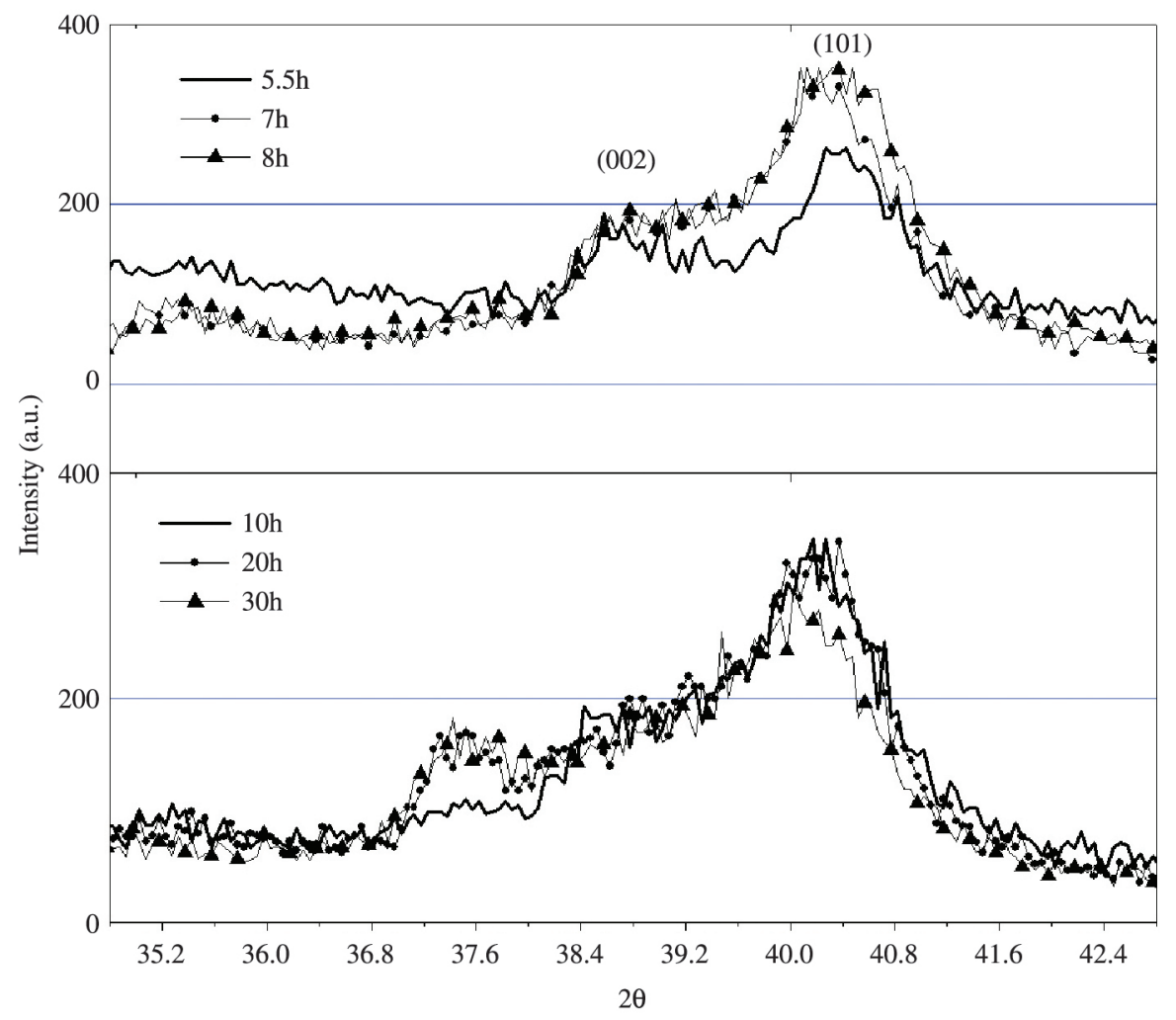

Figure 3. XRD results of Ti-7.5Si-22.5B powders obtained through the MR 1.

Table 1. Oxygen and nitrogen contents of the Ti-Si-B materials (wt.-\%).

\begin{tabular}{lccc}
\hline \multicolumn{1}{c}{$\begin{array}{c}\text { Analyzed } \\
\text { Material }\end{array}$} & $\begin{array}{c}\text { Milling Time } \\
\text { of the powder } \\
\text { used (h) }\end{array}$ & Oxygen & Nitrogen \\
\hline Elemental powder & 0.0 & 0.065 & 0.004 \\
As-milled powder $(7 \mathrm{~h})$ & 7.0 & 0.249 & 0.036 \\
$\mathrm{PS}\left(\mathrm{LV}\right.$ at $\left.1100^{\circ} \mathrm{C}\right)$ & 30.3 & 1.160 & 0.109 \\
$\mathrm{PS}\left(\mathrm{LV}\right.$ at $\left.1200^{\circ} \mathrm{C}\right)$ & 30.3 & 1.490 & 0.081 \\
$\mathrm{PS}\left(\mathrm{HV}\right.$ at $\left.1100^{\circ} \mathrm{C}\right)$ & 30.3 & 0.964 & 0.051 \\
$\mathrm{PS}\left(\mathrm{HV}\right.$ at $\left.1100^{\circ} \mathrm{C}\right)$ & 30.0 & 0.669 & 0.095 \\
Hot pressing & 1.0 & 0.457 & 0.130 \\
\hline
\end{tabular}

SEM analyses of the powders show a variety of sizes and morphologies that were obtained with the different processing parameters (Figure 2). The powder obtained after 1 hour through MR 2a exhibits irregular morphology and maximum particle size of about $700 \mu \mathrm{m}$ (Figure 2d). Powders obtained through wet milling reveal also irregular morphology, however the maximum particle size is significantly smaller (around $80 \mu \mathrm{m}$ ). Particles with flake morphology are also observed. EDS analysis detected $\mathrm{Fe}, \mathrm{Cr}$ and $\mathrm{Ni}$ as the major impurities in the as-milled powders. The iron pick-up increases with milling time reaching 3.28 at.\% after 32 hours (MR 1), which is the maximum registered value of all mixtures. Chromium contamination of 0.43 at. $\%$ was found after 8 hours of milling, however $\mathrm{Cr}$ and $\mathrm{Ni}$ were not detected in the remaining as-milled powders (MR 1). The as-milled powders obtained through the MR 2 presented 3.07 at. $\%$ of iron and 2.28 at.\% of nickel.

Oxygen and nitrogen contents of powders and sintered samples are listed in Table 1. Such impurities increased even using argon atmosphere, nevertheless this inert gas avoided higher values that would form oxides and nitrides. These values are still close to the verified in as-milled Ti-Al-Nb powders processed with a higher purity argon atmosphere ${ }^{9}$.

Wet milling has inhibited formation of new phases, however $\mathrm{O} / \mathrm{N}$ contents increased significantly as listed in Table 1. This final milling step was performed to pull out the sticked powders from the milling media, which probably removes layers with different chemical composition. XRD patterns in Figure 4 show differences that can be related to changing of crystallite sizes and/or chemical composition as presented in other works ${ }^{10,11}$.

XRD and SEM results (Figures 5 and 6) of the sintered alloys demonstrate a major formation of the $\alpha-\mathrm{Ti}, \mathrm{Ti}_{6} \mathrm{Si}_{2} \mathrm{~B}$, $\mathrm{TiB}$ and $\mathrm{Ti}_{5} \mathrm{Si}_{3}$ phases, besides a minor formation of $\mathrm{Ti}_{3} \mathrm{Si}$ (only in the hot-pressed sample). EDS analyses indicated regions with silicon contents of 20.8 at.-\%, which can be related to the $\mathrm{Ti}_{6} \mathrm{Si}_{2} \mathrm{~B}$ phase. Furthermore, an iron contamination close to 6.0 at. $\%$ was detected in the brighter regions that were named of $\mathrm{Ti}_{\mathrm{ss}}$ (ss-solid solution). The effect of the milling time is well characterized by the SEM images, since a lamellar structure (Figure 6b) was formed using powders processed by short times of milling, which is a feature of processing of ductile powders. Sintering of 


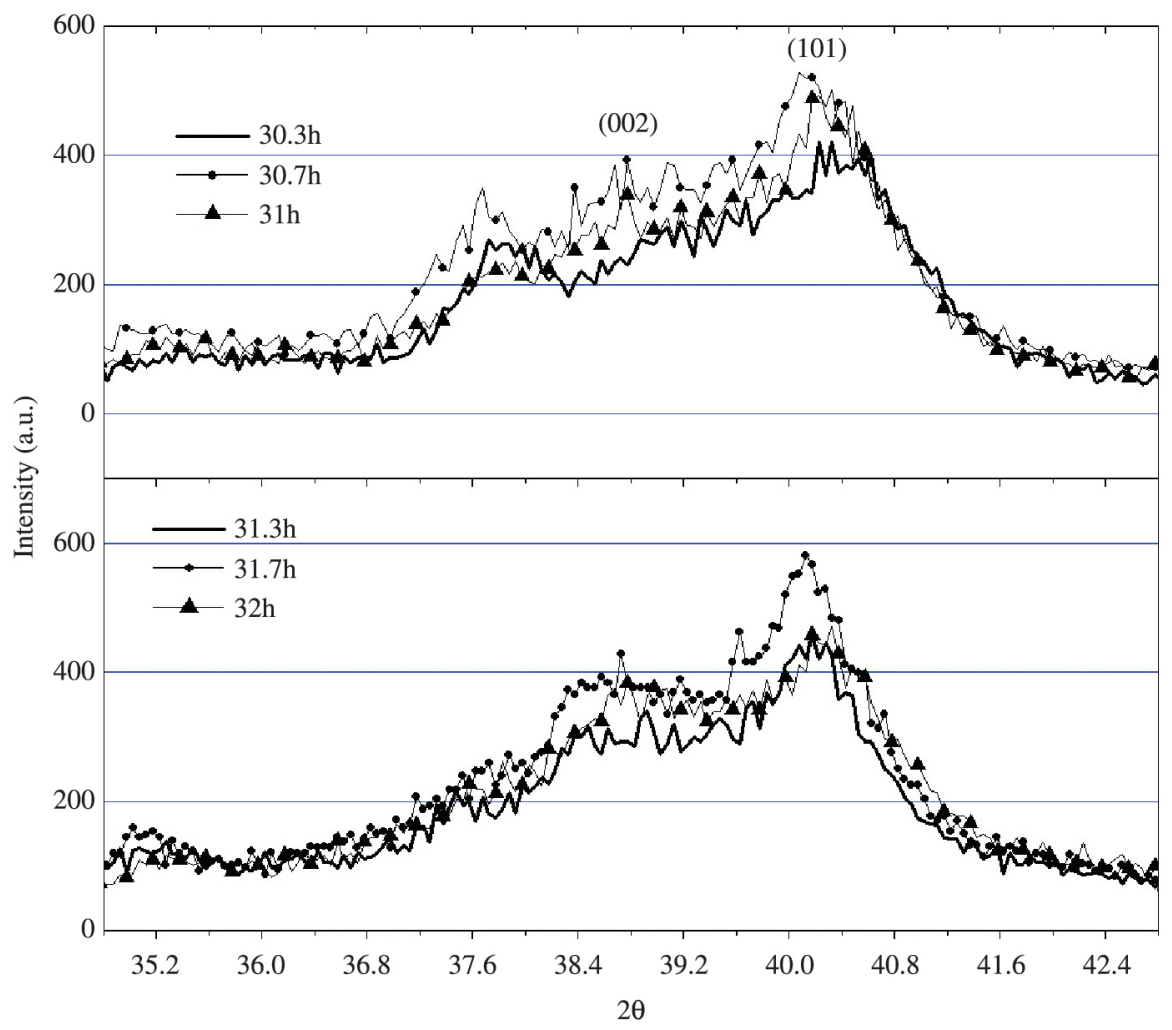

Figure 4. XRD results of Ti-7.5Si-22.5B powders obtained through the MR 1 in wet medium.

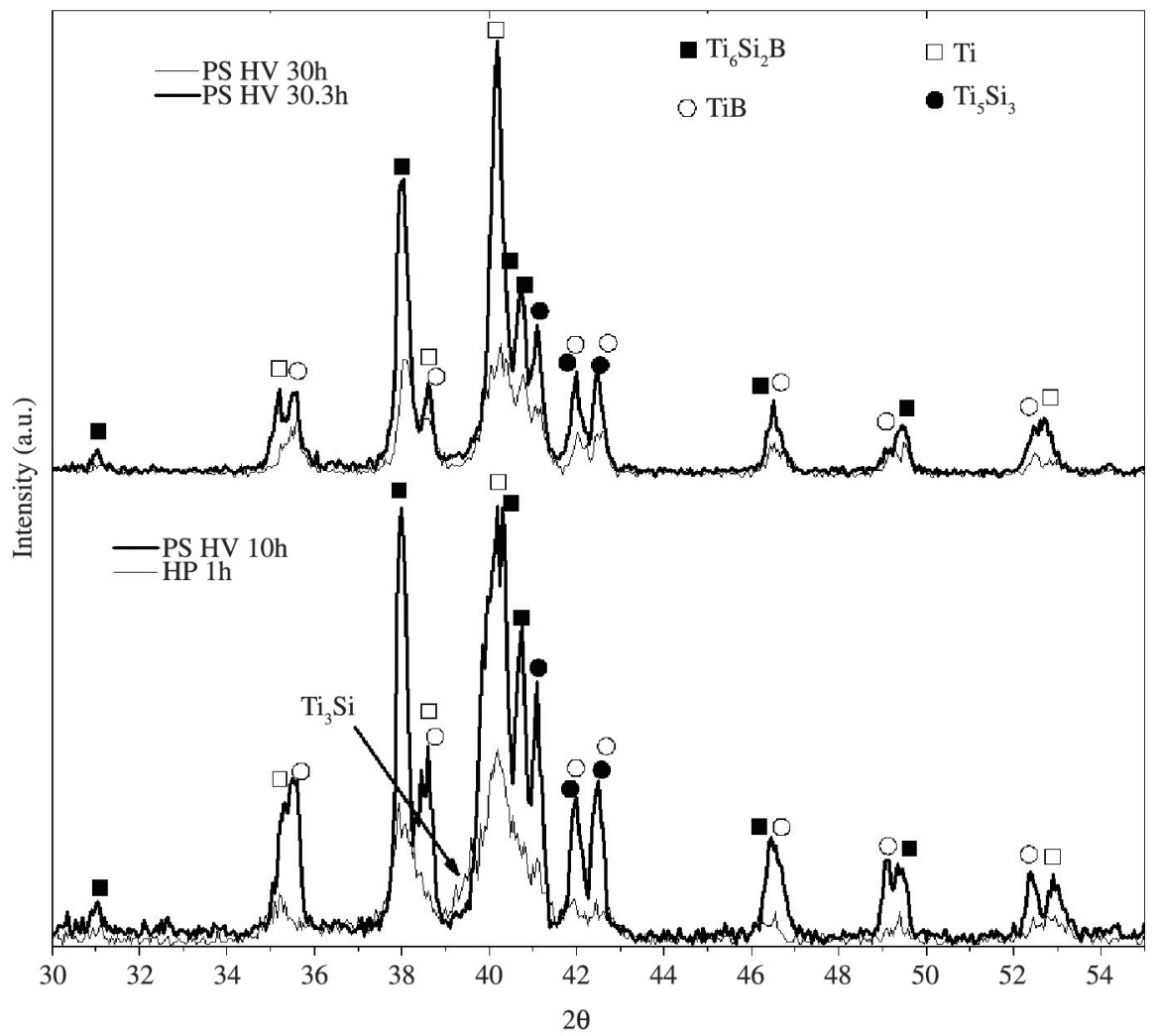

Figure 5. XRD results of the Ti-7.5Si-22.5B alloys obtained through pressureless sintering under high vacuum and hot pressing. 


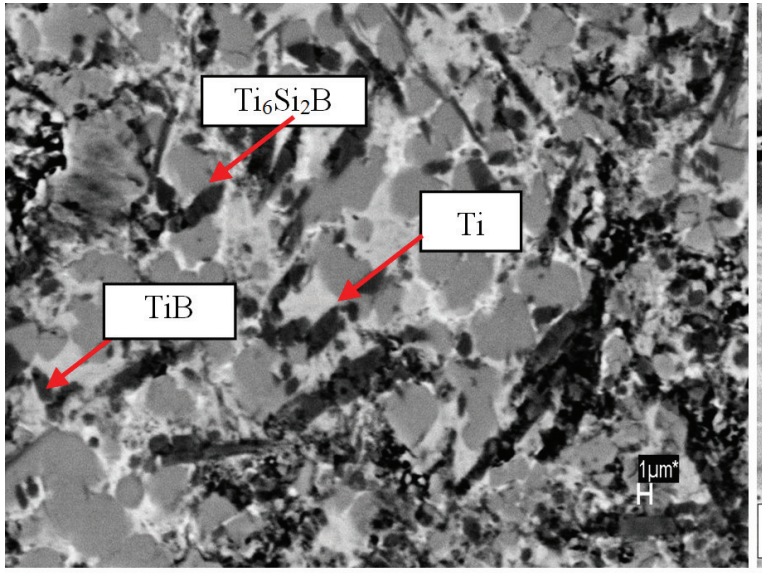

(a)

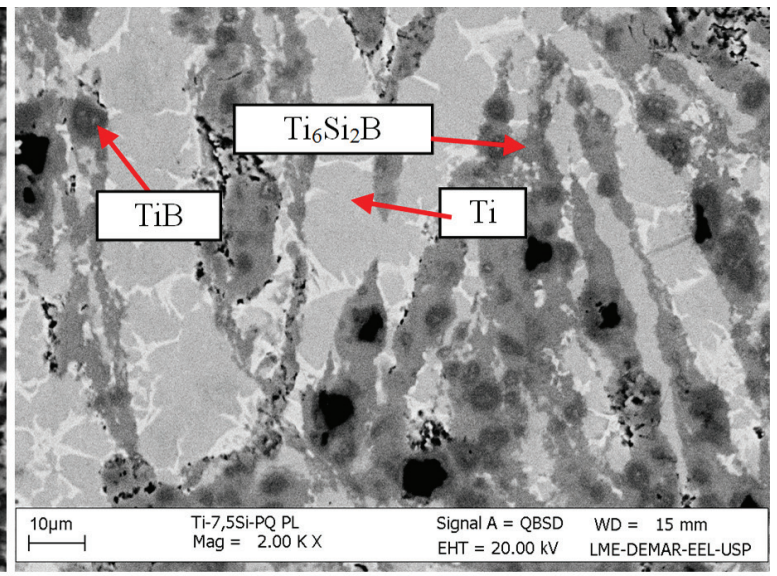

(b)

Figure 6. SEM images of the Ti-7.5Si-22.5B alloys obtained through: (a) PS HV with powders milled for 30 hours (MR 1); (b) and HP with powders milled for 1 hour (MR 2a).

Table 2. Data of the Ti-7.5Si-22.5 alloys

\begin{tabular}{lcccc}
\hline $\begin{array}{c}\text { Sintering } \\
\text { Condition }\end{array}$ & $\begin{array}{c}\text { Milling Mode and Time } \\
\text { of the Powders Used }\end{array}$ & $\begin{array}{c}\text { Vickers } \\
\text { Hardness }\end{array}$ & $\begin{array}{c}\text { Standard } \\
\text { Deviation }\end{array}$ & $\begin{array}{c}\text { Density } \\
\left(\mathbf{g} / \mathbf{c m}^{\mathbf{3}}\right)\end{array}$ \\
\hline PS (HV at $\left.1100^{\circ} \mathrm{C}\right)$ & Mode 1 (10 hours) & - & - & 2.27 \\
PS (HV at $\left.1100^{\circ} \mathrm{C}\right)$ & Mode 1 (30 hours) & 417.40 & 252.33 & 2.86 \\
PS (HV at $\left.1100^{\circ} \mathrm{C}\right)$ & Mode 1 (30.3 hours) & 280.58 & 73.80 & 2.83 \\
PS (LV at $\left.1100^{\circ} \mathrm{C}\right)$ & Mode 1 (30.3 hours) & 297.08 & 79.66 & 2.95 \\
PS (LV at $\left.1100^{\circ} \mathrm{C}\right)$ & Mode 1 (30.7 hours) & 209.83 & 11.28 & 2.98 \\
PS (LV at $\left.1200^{\circ} \mathrm{C}\right)$ & Mode 1 (30.3 hours) & 305.13 & 21.05 & 3.10 \\
Hot pressing & Mode 2a (1 hour) & 831.55 & 58.83 & 4.38 \\
\hline
\end{tabular}

as-milled powders processed for longer times (Figure 6a) promotes the reduction of the layer spacing or even their disappearance ${ }^{9}$, however, further production of samples with the same sintering conditions must be carried out to confirm such affirmation.

The sintering parameters were not enough to complete the expected diffusion that is required to obtain the threephase equilibrium structure. Conditions of fabrication and the properties of the sintered samples are listed in Table 2. Note that under the same sintering conditions, the compact containing coarser particles (milled for 10 hours, majority $>100 \mu \mathrm{m}$ ) reached only a density of $2.27 \mathrm{~g} / \mathrm{cm}^{3}$, while the compact with finer particles (milled for 30.3 hours, $<60 \mu \mathrm{m}$ ) presents density of $2.83 \mathrm{~g} / \mathrm{cm}^{3}$. Cold isostatic pressing had not increased the densification of the latter sample. Probably, sintering temperatures below $1200^{\circ} \mathrm{C}$ are not high enough to promote high densities in the samples when compared to similar work ${ }^{4}$.

Despite the similar densities of the compacts at lines 2 and 3 (Table 2), their hardness values are different due to variables as composition, particle size and contamination. Higher hardness values may be related to the lower intensity of XRD peaks, finer particles and oxide phases. Even with much more TiB content, the hardness values of the PS samples are similar to those reported in previous work ${ }^{1}$. However, hardness and densification increase significantly when HP is used, as shown in previous research using current-activated pressure-assisted sintering (CAPAS) $)^{[7]}$. Densification of the Ti-7.5Si-22.5B powders was improved due to the use of powders milled for only 1 hour comparing with HP of elemental powders without milling ${ }^{20}$. This phenomenom is explained in other papers ${ }^{9,12}$. Compression studies have been performed verifying a very low ductility $(<0.1 \%)$ of Ti-Si-B sintered alloys produced through $\mathrm{HP}$, however, the strength is high $(>1000 \mathrm{MPa})^{[21]}$. Also, further tensile and impact tests as well as more compression experiments must be performed in these sintered alloys.

\section{Conclusions}

A higher powder yield was verified for powders produced through the MR 2 due to the higher times that were adopted for those of the MR 1. Furthermore, particle sizes are larger for the powders processed through the MR $2 \mathrm{~b}$ and reduction of the XRD peaks is similar for the analyzed routes. This information is useful for the development of new hard coatings and the improvement of manufacturing process, which demand of scientific data.

Metastable structures (extended solid solution and amorphous phases) can be formed after milling process of powder mixtures with initial composition Ti-7.5Si-22.5B (at.\%). Such formation is independent of MR described 
in the present manuscript, although a minimum time of 20 hours must be employed to achieve these structures.

SEM/EDS and XRD analyses showed the formation of the $\alpha-\mathrm{Ti}, \mathrm{Ti}_{6} \mathrm{Si}_{2} \mathrm{~B}, \mathrm{TiB}$ and $\mathrm{Ti}_{5} \mathrm{Si}_{3}$ phases due to the sintering of the as-milled Ti-7.5Si-22.5B powders. Such analyses also indicate that the iron picked-up during milling process is preferentially segregated in $\mathrm{Ti}_{\mathrm{ss}}$ regions. Iron contamination was detected by EDS with values of around 3.0 at. $\%$ in the powders and 6.0 at.\% in the bulk $\left(\mathrm{Ti}_{\mathrm{ss}}\right)$.

Pressureless sintering produced compacts with higher porosity and low hardness (maximum of $420 \mathrm{HV}$ ). However, the sintered alloy produced using hot pressing had significantly less porous, which ruminate in a higher hardness (around $800 \mathrm{HV}$ ). All materials produced in this work can be employed in plasma experiments as sputtering targets in order to evaluate the effects of porosity and

\section{References}

1. Firstov SO, Horna ID, Horpenko KO, Beha MD, Koval OY and Kotko AV. Structure and physicomechanical properties of eutectic Ti-Si-X alloys. Materials Science. 2008; 44(3):342351. http://dx.doi.org/10.1007/s11003-008-9089-8

2. Audronis M, Leyland A, Matthews A, Kiryukhantsev-Korneev FV, Shtansky DV and Levashov EA. The Structure and Mechanical Properties of Ti-Si-B Coatings Deposited by DC and Pulsed-DC Unbalanced Magnetron Sputtering. Plasma Processes and Polymers. 2007; 4:S687-S692. http://dx.doi. org/10.1002/ppap.200731706

3. Shtansky DV, Sheveiko AN, Petrzhik MI, KiryukhantsevKorneev FV, Levashov EA, Leyland A et al. Hard tribological Ti-B-N, Ti-Cr-B-N, Ti-Si-B-N and Ti-Al-Si-B-N coatings. Surface and Coatings Technology. 2005; 200:208-212. http:// dx.doi.org/10.1016/j.surfcoat.2005.02.126

4. Korosteleva EN, Pribytkov GA and Gurskikh AV. Bulk changes and structurization in solid-phase sintering of titanium-silicon powder mixtures. Powder Metallurgy and Metal Ceramics. 2009; 48(1-2):8-12. http://dx.doi.org/10.1007/ s11106-009-9104-0

5. Thadhani NN, Graham RA, Royal T, Dunbar E, Anderson MU and Holman GT. Shock-induced chemical reactions in titanium-silicon powder mixtures of different morphologies: Time-resolved pressure measurements and materials analysis. Journal of Applied Physics. 1997; 82(3):1113-1128. http:// dx.doi.org/10.1063/1.365878

6. Zhang Z-H, Shen X-B, Wen S, Luo J, Lee S-K and Wang F-C. In situ reaction synthesis of $\mathrm{Ti}-\mathrm{TiB}$ composites containing high volume fraction of $\mathrm{TiB}$ by spark plasma sintering process. Journal of Alloys and Compounds. 2010; 503:145-150. http:// dx.doi.org/10.1016/j.jallcom.2010.04.218

7. Patel VV, El-Desouky A, Garay JE and Morsi K. Pressure-less and current-activated pressure-assisted sintering of titanium dual matrix composites: Effect of reinforcement particle size. Materials Science and Engineering: A. 2009; 507:161-166. http://dx.doi.org/10.1016/j.msea.2008.11.046

8. Ramos AS, Nunes CA, Rodrigues G, Suzuki PA, Coelho GC, Grytsiv A et al. $\mathrm{Ti}_{6} \mathrm{Si}_{2} \mathrm{~B}$, a new ternary phase in the Ti-Si-B system. Intermetallics. 2004; 12(5):487-491. http://dx.doi. org/10.1016/j.intermet.2004.01.001

9. Suryanarayana C. Mechanical alloying and milling. Progress in Materials Science. 2001; 46:1-184. http://dx.doi.org/10.1016/ S0079-6425(99)00010-9 production methods on the properties of the respective coatings. Beyond the application as coating, Ti-7.5Si22.5B samples developed in this work can be used in high performance cutting tools and as abrasive element, as well as other special applications ${ }^{6}$.

\section{Acknowledgments}

The authors would like to thank the $C N P q$ (National Council of Research and Development) funding agency. The authors acknowledge João Bernardes for compaction and cutting operations, José Luis de Oliveira, Edevaldo Faria Diniz and Geraldo Pereira de Castro for sintering facilities and several co-workers at ITA, IAE and USP. FAPESP (processo 2011/00872-2). Dedicated to the memory of Professor Carlos de Moura Neto.

10. Sun JF, Wang MZ, Zhao YC, Li XP and Liang BY. Synthesis of titanium nitride powders by reactive ball milling of titanium and urea. Journal of Alloys and Compounds. 2009; 482:L29-L31. http://dx.doi.org/10.1016/j.jallcom.2009.04.043

11. Dabhade VV, Mohan TRR and Ramakrishnan P. Nanocrystalline titanium powders by high energy attrition milling. Powder Technology. 2007; 171:177-183. http://dx.doi.org/10.1016/j. powtec.2006.10.007

12. Scholl R, Böhm A and Kieback B. Fabrication of silicide materials and their composites by reaction sintering. Materials Science and Engineering: A. 1999; 261:204-211. http://dx.doi. org/10.1016/S0921-5093(98)01067-3

13. Silvério DM, Ramos ECT, Silva G, Ramos AS, Cardoso KR and Nunes CA. Syntheses of $\mathrm{TiB}$ and $\mathrm{TiB}_{2}$ by High-Energy Ball Milling. Journal of Metastable and Nanocrystalline Materials. 2004; 20-21:139-144. http://dx.doi.org/10.4028/ www.scientific.net/JMNM.20-21.139

14. Silva G, Ramos ECT, Silvério DM, Ramos AS, Cardoso $\mathrm{KR}$ and Nunes CA. Phase Transformations during the Preparation of $\mathrm{Ti}_{6} \mathrm{Si}_{2} \mathrm{~B}$ by High-Energy Ball Milling. Journal of Metastable and Nanocrystalline Materials. 2004; 2021:145-150. http://dx.doi.org/10.4028/www.scientific.net/ JMNM.20-21.145

15. Fernandes BB, Ramos AS and Suzuki PA. Preparation of $\mathrm{Ti}+\mathrm{Ti}_{6} \mathrm{Si}_{2} \mathrm{~B}+\mathrm{Ti}_{5} \mathrm{Si}_{3}$ and $\mathrm{Ti}+\mathrm{Ti}_{6} \mathrm{Si}{ }_{2} \mathrm{~B}+\mathrm{TiB}$ Powders by HighEnergy Ball Milling and Subsequent Heat Treatment. Journal of Metastable and Nanocrystalline Materials. 2005; 24 25:467-471. http://dx.doi.org/10.4028/www.scientific.net/ JMNM.24-25.467

16. Silva G, Ramos ECT and Ramos AS. Effect of Milling Parameters on the $\mathrm{TiB}$ and $\mathrm{TiB}_{2}$ Formation in Ti-50at\% $\mathrm{B}$ and Ti-66at\%B Powders. Materials Science Forum. 2008; 591:135140. http://dx.doi.org/10.4028/www.scientific.net/MSF.591593.135

17. Ramos ECT, Santos DR, Cairo CAA, Henriques VAR and Ramos AS. Effect of composition and milling parameters on the critical ball milling of Ti-Si-B powders. Journal of Alloys and Compounds. 2009; 483:190-194. http://dx.doi.org/10.1016/j. jallcom.2008.06.164

18. Silva AN, Silva G, Ramos AS, Paschoal AL, Ramos ECT and Filgueira M. Preparation of $\mathrm{Ti}+\mathrm{Ti}_{6} \mathrm{Si}_{2} \mathrm{~B}$ powders by high-energy ball milling and subsequent heat treatment. Intermetallics 2006; 14:585-591. http://dx.doi.org/10.1016/j. intermet.2005.08.005 
19. Joint Committee on Powder Diffraction Standards - JCPDS, International Centre for Diffraction Data. Powder File Phases. PCPDFWIN; 2002.

20. Fernandes BB, Ramos AS, Moura Neto C, Coelho GC and Suzuki PA. On Ti-18Si-6B and Ti-7.5Si-22.5B powder alloys prepared by high-energy ball milling and sintering. Materials
Research. 2012; 15(6):954-963. http://dx.doi.org/10.1590/ S1516-14392012005000130

21. Fernandes BB. Avaliação de propriedades físico-químicas de ligas Ti-Si-B produzidas por metalurgia do pó. [Tese]. Instituto Tecnológico de Aeronáutica; 2010. 